\title{
Focal Midbrain Glioma: Long Term Survival in a Cohort of 16 Patients and the Implications for Management
}

\author{
Mark G. Hamilton, Carl Lauryssen and Neil Hagen
}

\begin{abstract}
Background: Focal gliomas involving the midbrain tectum and tegmentum have been identified as having a better prognosis than diffuse tumors affecting the brain stem. However, only limited information is available concerning treatment effectiveness and long term outcome for these patients. Methods: A retrospective, population-based cancer registry survey was performed to assess the clinical features and treatment courses of patients with focal midbrain tumors. Results: Sixteen patients with midbrain gliomas were identified; eight had tectal gliomas and eight tegmental gliomas. Thirteen patients presented with symptoms related to hydrocephalus, and 12 required a ventriculoperitoneal shunt. Seven patients underwent surgery directed at the tumor. Eight patients underwent initial radiation therapy and none had initial chemotherapy. One patient diagnosed at age 18 months had a rapidly growing tumor after 14 months of follow up which has responded to chemotherapy. The mean survival of this patient population was 84 months (range 3-280 months) after diagnosis, with only one tumor related death occurring (280 months after diagnosis). Survival was not affected by tumor location within the midbrain (tegmental or tectal) or by whether radiation therapy was or was not administered. Conclusions: Patients with focal midbrain gliomas require symptom control aimed at treatment of hydrocephalus, or mass effect from the tumor. However the extended survival of this population suggests that routine aggressive surgical debulking is often not required. Furthermore, the routine use of radiation therapy or chemotherapy for all such patients is questioned.
\end{abstract}

RÉSUMÉ: Gliome en foyer du mésencéphale: survie à long terme dans une cohorte de 16 patients et implications pour le traitement. Introduction: On sait que les gliomes en foyer impliquant le toit du mésencéphale ou la calotte, ont un meilleur pronostic que les tumeurs diffuses du tronc cérébral. Cependant, il existe peu d'information sur l'efficacité du traitement et l'issue à long terme chez ces patients. Méthodes: Nous avons effectué une étude rétrospective de population au moyen d'un registre de cancers afin de déterminer les caractéristiques cliniques et le mode de traitement des patients atteints de tumeurs en foyer du mésencéphale. Résultats: Seize patients porteurs de gliomes du mésencéphale ont été identifiés; huit avaient des gliomes du toit et huit avaient des gliomes de la calotte. Treize patients avaient consulté pour des symptômes en relation avec une hydrocéphalie et 12 avaient eu besoin d'une dérivation ventriculopéritonéale. Sept patients ont subi une chirurgie pour leur tumeur. Huit patients ont eu d'abord de la radiothérapie et aucun n'a eu initialement une chimiothérapie. Un patient, diagnostiqué à l'âge de 18 mois, avait une tumeur dont la croissance a été rapide au cours des 14 mois de suivi. Ce patient a bien répondu à la chimiothérapie. La survie moyenne de cette population de patients était de 84 mois (écart de 3 à 280 mois) après le diagnostic. Un seul décès était en relation avec la tumeur (280 mois après le diagnostic). La survie n'était pas influencée par le site de la tumeur dans le mésencéphale (à la calotte ou au toit) ou par l'administration de radiothérapie. Conclusions: Nous concluons que les patients qui ont des gliomes en foyer du mésencéphale ont besoin qu'on contrôle leurs symptômes en traitant leur hydrocéphalie ou l'effet de masse de la tumeur. Cependant, la survie prolongée de ces patients suggère qu'une chirurgie agressive effectuée de routine n'est souvent pas requise. De plus, nous remettons en question l'administration de routine de radiothérapie ou de chimiothérapie chez ces patients.

Can. J. Neurol. Sci. 1996; 23: 204-207

Intrinsic tumors of the brain stem are common in the pediatric population, comprising about $10 \%$ to $20 \%$ of all pediatric brain tumors and about $1 \%$ of adult brain tumors. ${ }^{\prime}$ While the prognosis of patients with diffuse pontine glioma remains poor, even with radiation therapy and chemotherapy, ${ }^{2-6}$ a number of subgroups of focal brain stem tumors have been identified that have a more benign course. These brain stem glioma subgroups include focal medullary glioma, ${ }^{7}$ dorsally exophytic brain stem glioma, ${ }^{8,9}$ tectal glioma, ${ }^{10-15}$ and focal midbrain glioma (also including tectal glioma). ${ }^{16}$ The identification of focal midbrain glioma as having a more favorable prognosis was first reported by Vandertop et al. ${ }^{16}$ in 1992 . Their population of 12 children had a mean followup of 2.5 years. Squires et al. ${ }^{15}$ in 1994 reported a group of 12 children with tectal gliomas with a median

\footnotetext{
From the Department of Clinical Neuroscience ( $\mathrm{MGH}, \mathrm{Cl}, \mathrm{NH}$ ), and Tom Baker Cancer Center (MGH and NH), University of Calgary, Calgary. RECEIVED AUGUST 14, 1995. ACCEPTED IN FINAL FORM MARCH 25, 1996. Reprint requests to: Dr. Mark G. Hamilton, Alberta Children's Hospital, 1820 Richmond Road S.W., Calgary, Alberta, Canada T2T 5C7
} 
survival of 4.2 years. We report a population based survey of pediatric and adult patients with focal midbrain glioma (tectal and tegmental) who have been followed longitudinally for as long as two decades and document their treatment and their outcome.

\section{METHODS}

The Alberta Cancer Registry is a population-based registry, recording all pathological or clinical diagnoses of a neoplasm. All patients from southern Alberta registered with a diagnosis of a brain stem tumor between January 1, 1975 and December 31, 1993 were reviewed. In addition, discharge diagnoses from the three large tertiary care hospitals in southern Alberta were also reviewed. All patients from southern Alberta who had clinical, biopsy, or autopsy evidence of a brain stem glioma were included if the neoplasm exclusively or mainly involved the midbrain. Midbrain tumors were classified into those which predominantly involved the tectum or predominantly involved the tegmentum. Hospital and cancer facility charts were reviewed to abstract clinical, pathological, and radiographic information. All available imaging studies were reviewed. The followup period for outcome ended June 30, 1994. Standard chi-squared statistical methods were employed to analyze the differences found among the patient groups.

\section{Results}

Over the two decade study period, 16 patients were identified with glioma which was entirely or mainly involving the midbrain; there were 11 males and 5 females (Table 1). At the time of initial presentation, six patients had headache, 5 patients had nausea or vomiting, 8 had cranial nerve palsies, 8 had ataxia, and one had altered level of consciousness secondary to hydrocephalus. All patients had a computed tomography (CT) scan, and 10 patients also had a magnetic resonance (MR) scan confirming the presence of midbrain glioma (see Figures 1 and 2 for MRI examples of typical tectal and tegmental gliomas). The tumor was predominately confined to the tectum in 8 patients, and predominately involved the tegmentum in 8 patients.

Thirteen patients had hydrocephalus and 12 required treatment with a ventricular peritoneal shunt. The remaining patient with hydrocephalus experienced complete resolution after surgical resection of the tumor. Three patients had biopsy only, and four had debulking surgery. There was no surgical mortality and no significant surgical morbidity. Pathology showed low grade glioma in 6, and necrosis only in one patient (failed biopsy). Eight patients underwent initial radiation therapy and none had initial chemotherapy.

Table 1: Patient Characteristics.

\begin{tabular}{lcc}
\hline & Mean & Range \\
\hline Age (years) & 20.4 & $1.5-64$ \\
\hline Gender & 11 male, 5 female \\
\hline $\begin{array}{l}\text { Duration of symptoms at } \\
\text { presentation (months) }\end{array}$ & 10.3 & $0.3-36$ \\
\hline
\end{tabular}

Table 2: Patient Outcome.

\begin{tabular}{lccc}
\hline & $\begin{array}{c}\text { Mean } \\
\text { followup } \\
\text { (months) }\end{array}$ & $\begin{array}{c}\text { Tumor } \\
\text { Related } \\
\text { Deaths }\end{array}$ & $\begin{array}{c}\text { Followup } \\
\text { range } \\
\text { (months) }\end{array}$ \\
\hline Whole Population $(n=16)$ & $84.4 \pm 66.5$ & 1 & $2-280$ \\
\hline
\end{tabular}

\begin{tabular}{llll}
\hline Radiation Therapy $(\mathrm{n}=8) \dagger$ & $111.3 \pm 70.6$ & 1 & $27-280$ \\
\hline No Radiation Therapy $(\mathrm{n}=8)$ & $57.5 \pm 49.1$ & 0 & $2-147$ \\
\hline
\end{tabular}

\begin{tabular}{cccc}
\hline $\begin{array}{c}\text { Primary Tegmental Glioma } \\
(\mathrm{n}=8) \ddagger\end{array}$ & $100.9 \pm 80.6$ & 1 & $2-280$ \\
\hline Primary Tectal Glioma $(\mathrm{n}=8)$ & $67.9 \pm 42.3$ & 0 & $14-125$ \\
\hline
\end{tabular}

$\dagger$ Difference between two groups not significant $\left(X^{2} ; p=0.36\right)$

$\ddagger$ Difference between two groups not significant $\left(\chi^{2} ; \mathrm{p}=0.11\right)$

Mean survival was $84 \pm 66$ months (range: 3-280) with only one tumor-related death (at 280 months, or 23 years after diagnosis). A second patient died of an unrelated abdominal aortic aneurysmal rupture with no evidence of tumor growth after 32 months (autopsy confirmed). One patient, diagnosed at age 18 months, had a rapidly growing tumor and rapidly deteriorating clinical condition by age 32 months, 14 months after initial tumor diagnosis. This patient is currently receiving adjuvant chemotherapy and has demonstrated tumor regression and dramatic clinical improvement. In all other patients there has been little or no tumor growth. Survival (Table 2) was not significantly different whether radiation therapy was or was not administered ( $11 \mathrm{I}$ and 58 months, respectively; $\mathrm{p}=0.36$ ). The apparent difference in survival numbers between these two treatment groups reflects changing management strategies over time: $6 / 8$ patients treated with radiation were diagnosed greater than 90 months ago, while only $2 / 8$ patients not treated with radiation were diagnosed greater than 90 months ago. Therefore, in this cohort

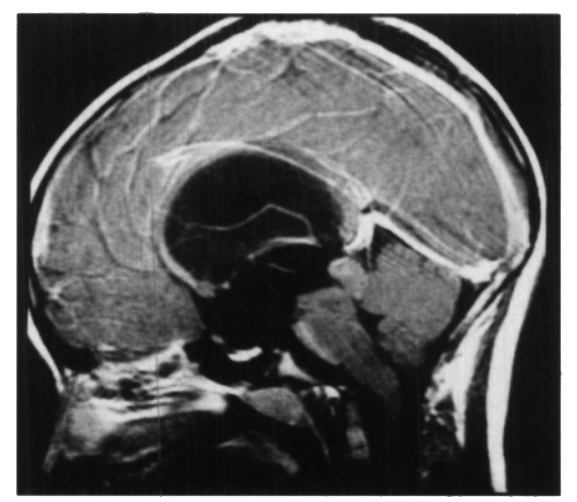

Figure 1: MRI example of a patient with a tectal glioma. This 9-yearold boy presented with symptoms of headache, decreased cognitive function, and gait disturbance. His physical examination demonstrated papilledema and gait apraxia. This $T 1$-weighted sagittal image demonstrates a thickened tectum that is characteristic for this diagnosis, and is associated with hydrocephalus. Treatment of this patient's hydrocephalus was accomplished with a ventriculo-peritoneal shumt with complete resolution of his presenting symptoms. There has been no tumor progression during 3 years of followup. 
patients who have been treated with radiation therapy have had a longer duration of followup. Survival was not significantly different whether the tumor location was predominantly tectal or tegmental (68 and 101 months, respectively; $\mathrm{p}=0.11$ ). Only $2 / 8$ patients with tectal glioma received radiation therapy compared with $6 / 8$ patients with tegmental glioma.

\section{DisCussion}

The identification of distinct subgroups of patients with glioma of the brain stem who have a significantly better prognosis than those with diffuse pontine glioma assists in
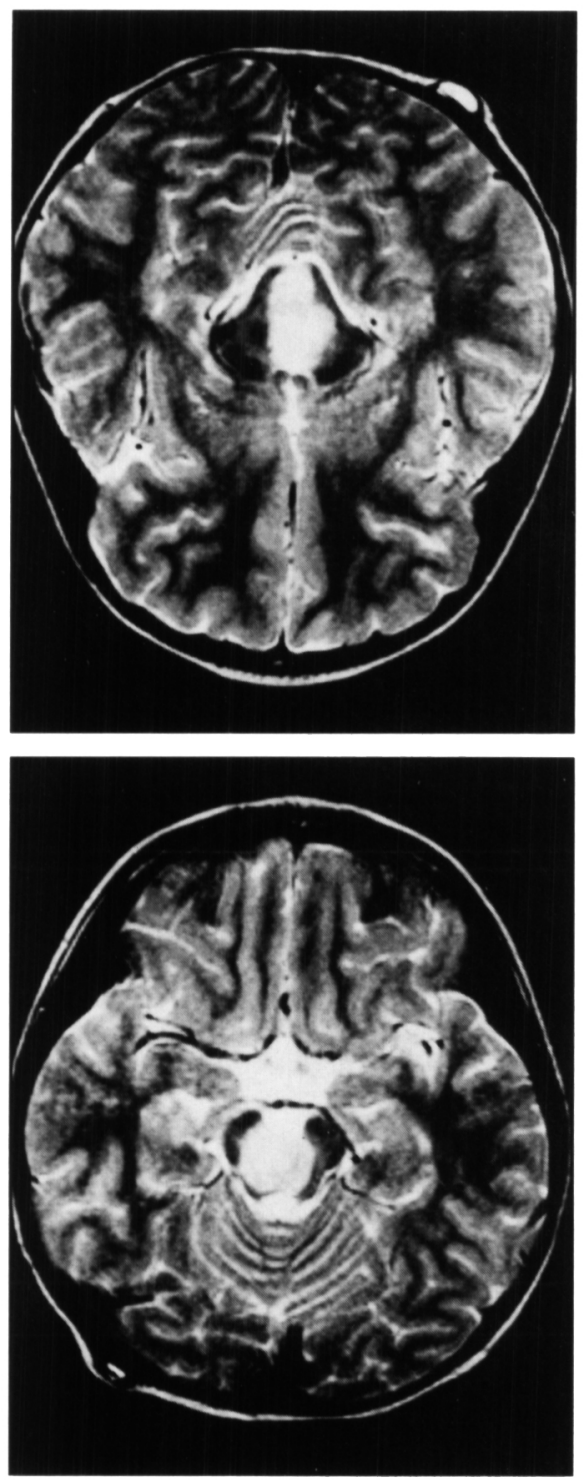

Figure 2a and $2 b$ : MRI example of a patient with a tegmental glioma. This 9-year-old boy presented with symptoms of headache and visual disturbance. His physical examination demonstrated papilledema and an incomplete right third nerve palsy. These two adjacent T2-weighted axial images ( $a$ and b) demonstrate tumor involving the entire midbrain tegmentum. This tumor was associated with hydrocephalus. Treatment of this patient's hydrocephalus was accomplished with a ventriculo-peritoneal shunt with resolution of his headaches and partial resolution of his diplopia. There has been no tumor progression during 2 years of followup. developing tumor-specific treatment strategies. ${ }^{17}$ Treatment decisions in brain stem tumor management are frequently made on the basis of clinical characteristics and imaging findings without biopsy. ${ }^{18,19}$ The current accepted treatment for diffuse pontine glioma is radiation therapy with or without chemotherapy and the survival of this patient subpopulation remains poor. ${ }^{1,2,6}$ Patients with focal gliomas have a predictably different natural history and should be considered for less aggressive management. The population of patients that the authors present substantiates and further extends our knowledge concerning the natural history of focal midbrain glioma.

High resolution CT and more recently MR imaging have provided the ability to identify intrinsic tumors of the brain stem with greater accuracy, at earlier stages of disease, and supply the detailed anatomical information that has allowed the clear distinction between focal and diffuse lesions. ${ }^{6,17.19-22}$ The radiologic features of midbrain gliomas have been described in other patient series, and no significant differences were detected in the patient cohort which is the subject of this report. ${ }^{1,12,15-17,20}$ Furthermore, CT and MR imaging have greatly reduced the need for diagnostic biopsy in the majority of patients with lesions of the brain stem. ${ }^{1,1720.22 .23}$ The differential diagnosis of brain stem lesions diagnosed with MR imaging includes other tumors such as ependymoma and ganglioglioma, and other lesions including cavernous malformations, ${ }^{23}$ multiple sclerosis, tuberculomas, parasitic cysts, and brain stem encephalitis.' The diagnostic accuracy of MR imaging, in juxtaposition with our understanding concerning the natural history of brain stem glioma suggests that little is gained from routine biopsy. ${ }^{13,17,18}$ Only three of the 16 patients in this series underwent a biopsy-only surgical procedure. In our center diagnostic biopsy is now not routinely performed if the MR imaging features are characteristic for brain stem glioma.

Tectal glioma as a distinct clinico-pathologic entity, was described by Sanford et al. ${ }^{10}$ in 1982 . These authors defined "tectal gliomas" as low-grade tumors confined to the aqueductal region of the tectum, producing hydrocephalus without cranial nerve palsies, truncal ataxia, pyramidal tract signs and other findings which characterize pontine gliomas. ${ }^{10}$ This initial report presented two patients diagnosed at postmortem examination, and identified 12 previous cases presented in the medical literature (all less than 19 years of age). Other authors have since reported additional patients that have substantiated the indolent natural history of this lesion with surgical treatment of symptomatic hydrocephalus. ${ }^{11-15,24}$ Two recent reports have presented patient cohorts with median followup ranging from 4.2 years ${ }^{15}$ to 5.5 years $^{12}$ with maximal followup as long as 17 years. ${ }^{12}$ The majority of patients described have been children, although three of these series include a small number of adults. ${ }^{1,13,14}$ The current recommended management of aqueductal glioma includes treatment of symptomatic hydrocephalus with either ventriculo-peritoneal shunting or endoscopic third ventriculostomy, and followup with regular clinical and MR examinations. At our center, endoscopic third ventriculostomy has become the preferred method for treating this type of obstructive hydrocephalus and has been used for the majority of these patients since late 1994 In the unusual situation of rapid tumor growth, more aggressive treatment (including surgery, radiation therapy, or chemotherapy) is indicated. ${ }^{15}$ 
The definition of the tectal (periaqueductal) region of the midbrain as a "privileged" location for gliomas that have a distinct indolent clinico-pathologic entity has recently been challenged by Vandertop et al..$^{16}$ to include other areas of the midbrain. Their cohort of 12 children included 6 patients with gliomas predominantly affecting the tectal region and 6 patients with tegmental gliomas. The mean followup of their 12 children was 2.5 years, ranging from 1 to 52 months in the 6 patients with gliomas of the tegmentum. These authors advocated the surgical treatment of such lesions: all 12 patients underwent surgery with or without adjuvant radiotherapy (6 patients). Surgery was performed predominantly to achieve improvement of neurologic deficit, with a major debulking achieved in $75 \%$ of their patients, and significant improvement in neurological function in 4 patients. There was no surgical mortality in this patient population, however, two patients had significant postoperative morbidity (transient hemiballismus and deep vein thrombosis in one patient and meningitis in another). The management strategy for patients with tegmental gliomas advocated by these authors is challenged by the natural history of the patient population presented in this paper.

This current report details a cohort of both pediatric and adult patients, with focal midbrain glioma (tectal and tegmental) who have a mean followup of almost a decade. The majority of these patients did not require tumor related surgery. While some patients did receive radiation treatment and had improvement of symptoms, there was no significant difference in survival whether or not radiation therapy was administered. The favorable survival and effective control of symptoms emphasizes the generally indolent natural history of focal gliomas of this location in both adults and children.

Treatment of patients with focal midbrain gliomas, both tectal and tegmental, should be directed at "symptom control". We recommend treatment of symptomatic hydrocephalus caused by focal midbrain glioma, preferabaly with endoscopic third ventriculostomy when possible. We also recommend surgical debulking of tumors with clinically significant symptomatic mass effect. Routine surgical debulking or biopsy, or use of primary radiation therapy or chemotherapy is challenged. Fourteen of 16 patients in this cohort failed to demonstrate evidence of clinically significant tumor progression over prolonged followup. Surgery, adjuvant therapy, or both should be considered only if the mass effect from the tumor is initially symptomatic or symptomatic expansion of the tumor occurs. Followup should include careful clinical observation and serial MR scans.

\section{REFERENCES}

1. Packer RJ, Nicholson HS, Vezina LG, Johnson DL. Brain stem gliomas. Neurosurg Clin North Am 1992; 3:863-879.
2. Grigsby PW, Thomas PR, Schwartz HG, Fineberg BB. Multivariate analysis of prognostic factors in pediatric and adult thalamic and brain stem tumors. Int J Radiat Oncol Biol Phys 1989; 16:649-655.

3. Mundinger F, Braus DF, Krauss JK, Birg W. Long-term outcome of 89 low-grade brain-stem gliomas after interstitial radiation therapy. J Neurosurg 1991; 75: 740-746.

4. Albright AL, Guthkelch AN, Packer RJ, Price RA, Rourke LB. Prognostic factors in pediatric brain-stem gliomas. J Neurosurgery 1986; 65: 751-755.

5. Maria BL, Eskin TA, Quisling RG. Brain stem and other malignant gliomas: II. Possible mechanisms of brain infiltration by tumor cells. J Child Neurol 1993; 8: 292-305.

6. Packer RJ, Nicholson HS, Johnson DL, Vezina LG. Dilemmas in the management of childhood brain tumors: brain stem gliomas. Pediatr Neurosurg 1991; 17: 37-43.

7. Abbott R, Shiminski-Maher T, Wisoff JH, Epstein FJ. Intrinsic tumors of the medulla: surgical complications. Pediatr Neurosurg 1991; 17: 239-244.

8. Hoffman HJ, Becker L, Craven MA. A clinically and pathologically distinct group of benign brain stem gliomas. Neurosurgery 1980; 7: 243-248.

9. Pollack IF, Hoffman HJ, Humphreys RP, Becker L. The long-term outcome after surgical treatment of dorsally exophytic brainstem gliomas. J Neurosurg 1993; 78: 859-863.

10. Sanford RA, Bebin J, Smith RW. Pencil gliomas of the aqueduct of Sylvius. J Neurosurg 1982; 57: 690-696.

11. Chapman PH. Indolent gliomas of the midbrain tectum. Concepts Pediatr Neurosurg 1990; 10: 97-107.

12. May PL, Blaser SI, Hoffman HJ, Humphreys RP, Harwood-Nash DC. Benign intrinsic tectal "tumors" in children. J Neurosurg 1991; 74: 867-871.

13. Steinbok P, Boyd MC. Periaqueductal tumor as a cause of late-onset aqueductal stenosis. Child's Nerv Syst 1987; 3: 170-174.

14. Boydston WR, Sanford RA, Muhlbauer MS, et al. Gliomas of the tectum and periaqueductal region of the mesencephalon. Pediatr Neurosurg 1991; 17: 234-238.

15. Squires LA, Allen JC, Abbott R, Epstein FJ. Focal tectal tumors: management and prognosis. Neurology 1994; 44:953-956.

16. Vandertop WP, Hoffman HJ, Drake JM, et al. Focal midbrain tumors in children. Neurosurgery 1992; 31: 186-194.

17. Maria BL, Rehder K, Eskin TA, et al. Brain stem glioma: I. Pathology, clinical features, and therapy. J Child Neurol 1993; 8: 112-128.

18. Sanford RA, Freeman CR, Burger P, Cohen ME. Prognostic criteria for experimental protocols in pediatric brain stem gliomas. Surg Neurol 1988; 30: 276-280.

19. Epstein F, Wisoff JH. Intrinsic brain stem tumors in childhood: surgical indications. J Neuro-Oncol 1988; 6:309-317.

20. Barkovich AJ, Krischer J, Packer R, et al. Brain stem gliomas: a classification system based on magnetic resonance imaging. Pediatr Neurosurg 1990; 16: 73-83.

21. Epstein F. A staging system for brain stem gliomas. Cancer 1985; 56: 1804-1806.

22. Smith RR. Brain stem tumors. Semin Roentgenol 1990; 25:249-262.

23. Hamilton MG, Wascher TM, Spetzler RF. Cavernous malformations of the brain stem. In: Da Pan R, Pasqualin A, ed. New Trends in Management of Cerebrovascular Malformations. New York: Spinger-Verlag, 1994: 525-532.

24. Raffel C, Hudgins R, Edwards MSB. Symptomatic hydrocephalus: initial findings in brain stem gliomas not detected on computed tomographic scans. Pediatrics 1988; 82: 733-737. 